\title{
THE VITAMIN B CONTENT OF CANCER
}

\author{
BY HENRY JACKSON, JR., AND CLEMENT I. KRANTZ \\ (From the Medical Service of the Collis P. Huntington Memorial Hospital of Harvard \\ University and the Thorndike Memorial Laboratory, Boston City Hospital)
}

(Received for publication September 17, 1928)

Burrows (1) has been led to believe that cancer may be due to a local excess of vitamin B in the tissue and he and his co-worker Jorstad bring forward some evidence that the Jensen rat sarcoma does actually contain an abnormally great amount of this accessory food substance (2) (3). They fed young rats a basic diet free from vitamin B to which were added ten grams Jensen rat sarcoma and from the growth curves obtained on this diet they conclude that cancerous tissue contains an abnormally great amount of vitamin $B$. No normal resting organ was, however, directly contrasted with the malignant tissue, so we are left in doubt as to the exact quantitative differences in vitamin $B$ content between normal and neoplastic tissue. If cancer really be due to, or associated with, an increase of vitamin B, then actively growing neoplastic tissue should, as Burrows claims, contain more of this accessory food factor than normal tissue. Experiments were therefore devised to check the results of Burrows and Jorstad as the matter is not without both theoretical and practical importance.

Young white rats were placed on a basic diet containing:

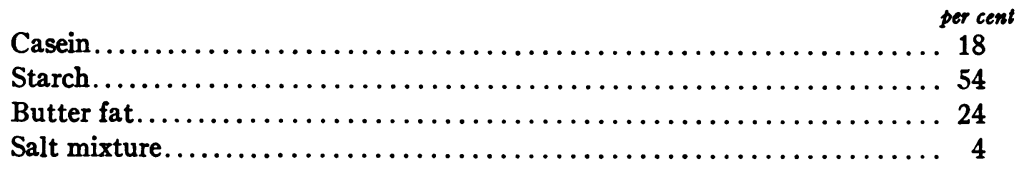

The salt mixture was that described by Osborne and Mendel (4). All ingredients were free from vitamin B. Each rat was kept in a separate cage and adequate precautions were taken against the consumption of feces. Tap water was given freely at all times. Each rat was weighed every two days. The basic vitamin B free diet was renewed daily. In addition to the basic diet each rat received in a separate 
dish a weighed portion of either dried human cancer, dried mouse cancer, dried normal mouse liver or vitamin B "Harris." The tissue was in each instance chopped fine while still fresh and then dried rapidly in a current of air at $50^{\circ} \mathrm{C}$., a procedure which Mendel (5) has shown to be satisfactory for the adequate preservation of vitamin B. The powdered tissue (or the yeast concentrate) was mixed with a little molasses and thus prepared was readily consumed by the rats

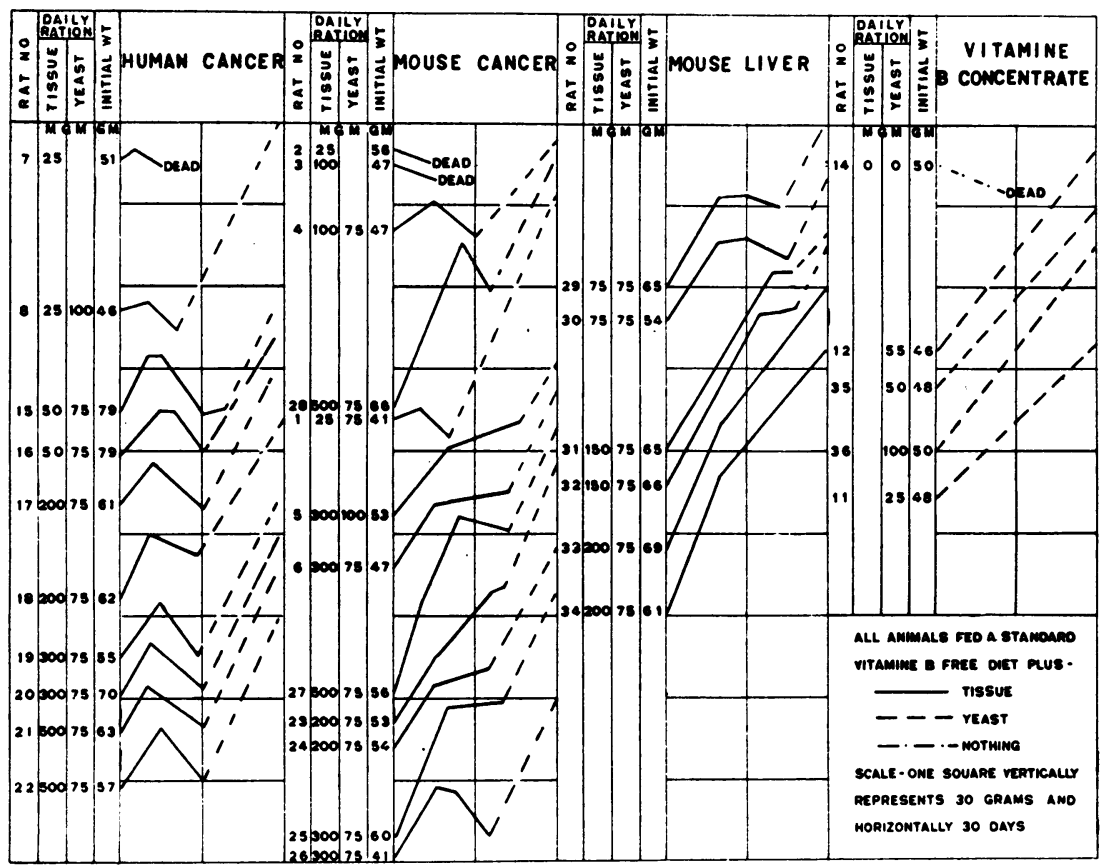

Chart 1. Weight Curves on Various Diets

daily. Each rat was kept on the experimental diet approximately 60 days, or, when tissue was being fed, until the individual weight curve showed that the supply of vitamin B from this source was definitely inadequate. After a fall in weight the animal was shifted to vitamin B "Harris," whch was given in varying but always adequate amounts. The subsequent weight curve indicated that in each case the loss of weight previously noted could be adequately checked by proper vitamin feeding, and was therefore due to this vitamin lack. 
Ten rats were fed human cancer, twelve were fed mouse cancer, six normal mouse liver, and four were placed on pure diets without addition of tissue (chart 1$)$.

An examination of chart 1 shows that even $500 \mathrm{mgm}$. dried human cancer per diem was insufficient to produce adequate growth. After a

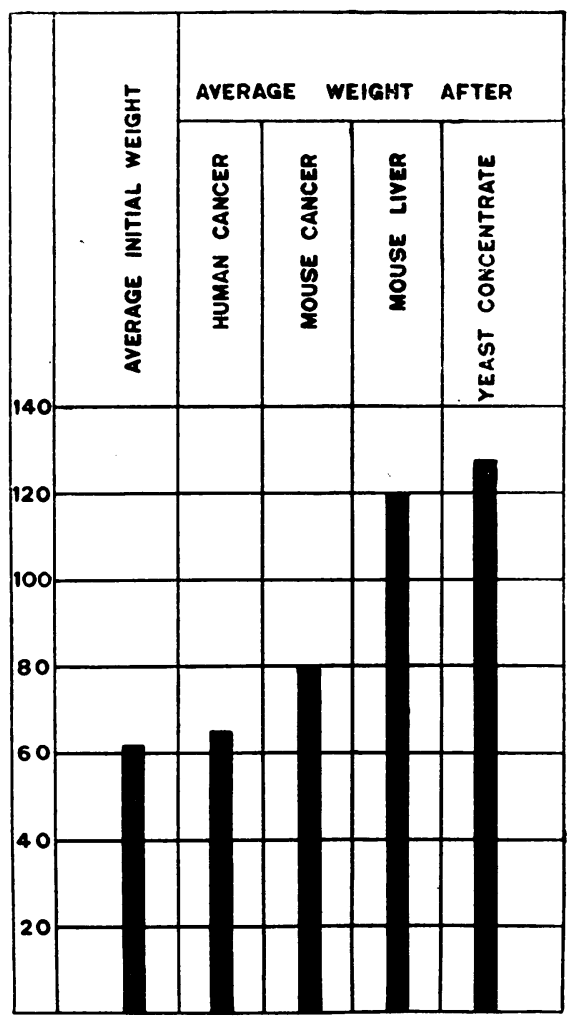

Chart 2. Average Weights at the Beginning of the Experiment and at the End of the Feeding Periods on Various Diets

preliminary increase in the weight of the animals presumably due to stored vitamin B there was in all instances a prompt and rapid fall in weight. This rise and fall will further be seen to be virtually independent of the amount of tissue fed-in this instance a rapidly growing carcinoma of the kidney removed at operation. The tumor was com-

THE JOURNAL OF CLINICAL INVESTIGATION, vol. vi, No. 4 
posed almost entirely of neoplastic cells. The stroma was negligible. The vitamin B content of human cancer would seem to be small, not large.

Mouse carcinoma, strain D Br., a very cellular mammary adenocarcinoma, gave somewhat more erratic growth curves; and 200 to $300 \mathrm{mgm}$. of this tumor dried did indeed cause a rapid initial rise in the rats' weight, but the effect was merely a transient one and again as in the case of human cancer, the tissue failed to support growth in an adequate fashion. It would appear that animal cancer contains no great excess of vitamin $B$.

Normal mouse liver, prepared in exactly the same way as the neoplastic tissue, contained more growth promoting vitamins than either of the malignant tissues studied. Two hundred mgm. (dry weight) a day gave rise to normal growth curves virtually identical with those obtained by feeding adequate amounts of vitamin B concentrate (Harris). Normal liver would seem from these results to be a most potent source of vitamin B and our results check well with those of Osborne and Mendel (5).

Chart 2 gives the average weights at the beginning of the experiment, and the average weights at the end of the feeding period on each source of vitamin. Here again it will be seen that neoplastic tissue is a less potent source of vitamin B than a normal resting organ such as liver.

We find no evidence that malignant tissue contains unusually large amounts of vitamin B. In fact it is inferior in this respect to normal liver. Such findings do not favor the hypothesis that malignant disease is due to or associated with excess vitamin B.

\section{BIBLIOGRAPHY}

1. Burrows, M. T., Arch. Int. Med., 1926, xxxvii, 453. The Mechanism of Cancer Metastasis.

2. Burrows, M. T., and Jorstad, L. H., Am. J. Physiol., 1926, lxxvii, 24. On the Source of Vitamin B in Nature.

3. Burrows, M. T., and Jorstad, L. H., Am. J. Physiol., 1926, lxxvii, 38. On the Source of Vitamin A in Nature.

4. Osborne, T. B., and Mendel, L. B., J. Biol. Chem., 1919, xxxvii, 572. The Nutritive Value of the Wheat Kernel and its Milling Products.

5. Osborne, T. B., and Mendel, L. B., J. Biol. Chem., 1923, lviii, 363. The Effect of Diet on the Content of Vitamine B in the Liver. 